Perinatology pISSN 2508-4887 • elSSN 2508-4895

\section{Original article}

Perinatology Vol. 31, No. 4, December, 2020

https://doi.org/10.14734/PN.2020.31.4.186

\title{
The Correlation between Maternal Ante- and Postpartum Depression and Mode of Delivery: Preliminary Study
}

\begin{abstract}
Hwa Seon Koo, MD, PhD', Young Ran Kim, MD, PhD', Jin Young Park, MD, PhD', Kyungun Jhung, MD, $\mathrm{PhD}^{3}$, Kyungmi Chung, MD, PhD', Hee Young Cho, MD, PhD ${ }^{1}$
\end{abstract}

'Department of Obstetrics and Gynecology, CHA Bundang Medical Center, CHA University, Seongnam; ${ }^{2}$ Department of Psychiatry \& Institute of Behavioral Science in Medicine, Yonsei University College of Medicine, Seoul; ${ }^{3}$ Department of Psychiatry \& Behavioral Neuroscience, International St. Mary's Hospital, Catholic Kwandong University College of Medicine, Incheon, Korea

Received: 7 November 2019

Revised: 30 June 2020

Accepted: 24 July 2020

Correspondence to

Hee Young Cho, MD

Department of Obstetrics and Gynecology, CHA Bundang Medical Center, CHA University, 59 Yatapro, Bundang-gu, Seongnam 13496, Korea

Tel: +82-31-780-5290

Fax: +82-31-780-5069

E-mail: hycho.md@cha.ac.kr

Copyright@ 2020 by The Korean Society of Perinatology

This is an Open Access article distributed under the terms of the Creative Commons Attribution Non-Commercial License (http://creativecommons.org/ license/by-nc/4.0/), which permits unrestricted non-commercial use, distribution, and reproduction in any medium, provided that the original work is properly cited.
Objective: To investigate the relationship of prenatal and postnatal depression and mode of delivery. Methods: The study population consisted of 35 pregnant women who underwent antenatal care in Bundang CHA Medical Center from October 2018 to September 2019. Among them, 20 women underwent cesarean section (c-sec) and 15 women underwent vaginal delivery (VD). The survey was conducted at 34 to 36 gestational weeks and at postpartum 4 weeks consecutively using Korean version of Edinburgh Perinatal/Postnatal Depression Scale (EPDS). To evaluate the association between maternal ante- and postpartum depression and mode of delivery, we analyzed the differences of EPDS according to mode of delivery and pre- and postpartum.

Results: The mean scores of EPDS before delivery was 7.2 \pm 5.0 in C-sec group and 5.8 \pm 4.7 in VD group, but it was not statistically significant $(P=0.390)$. The EPDS scores at postpartum was significantly higher in women who underwent $C$-sec compared to VD group (9.2 \pm 4.9 vs. 7.6 $\pm 5.4, P=0.010$; respectively). Also when comparing the mode of delivery in fourteen women with EPDS 9 or above at postpartum, $C$-sec rate (64.3\%) was significantly higher than VD rate (35.7\%) $(P=0.010)$. In both groups, the scores of EPDS were increased after delivery with statistical significance $(P=0.039)$.

Conclusion: C-sec delivery could increase the EPDS at postpartum and delivery itself could result in maternal depressive symptoms during postpartum period regardless of mode of delivery.

Key Words: Cesarean section, Delivery, Depression, Psychiatric status rating scale

\section{서론}

우울과 불안은 임신 중에 산모가 겪는 흔한 증상 중 하나이며 이는 산모와 태아의 건강에 영향을 미치는 것으로 알려져 있다. ${ }^{1}$ 임신 중 우울 증상을 격는 산모는 대상군이 속해 있는 나라의 경제적인 상황에 따라서 다르지만 $12-16 \%$ 까지 보고되고 있다. ${ }^{2}$

지금까지의 여러 연구에서 임신 중 우울 또는 불안이 조산 및 태아 성장 지연 등의 산과적 합병증과 관련이 있다는 연구 결과가 발표되었지만, ${ }^{3}$ 연구에 따라서 일정한 결론을 도출하 기는 힘든 상황이었다. 하지만 최근의 메타분석에 의하며 임신 중 산모의 불안은 조산, 저체 중아, 작은 머리 둘레 등의 산과적 합병증과도 연관이 있는 것으로 알려졌다. ${ }^{4}$ 앞서 언급한 임신 중 우울 또는 불안과 산과적 합병증과의 연관성에 관한 연구에 비하여, 임신 중 우울과 불안이 분만 방법에 영향을 미치는지에 관한 연구 결과는 매우 제한적이며 결과의 일관성도 없는 상태이다. ${ }^{25,6}$

반대로 분만 방법이 산후우울증에 미치는 영향에 대한 연구도 이루어지고 있으며 이 또한 연구에 따라 다른 결과들을 보여주고 있다. 최근에 시행된 메타분석에서는 제왕절개를 통한 분만 자체가 산후우울증의 위험 요인이 될 수 있다고 설명하고 있다. ${ }^{7}$ 하지만 분만 전의 산모 의 우울 정도가 분만에 미치는 영향이나 분만 자체가 산모의 우울에 미치는 영향 등, 산모의 우울과 분만과의 연관성에 대한 다양한 연구는 부족한 실정이다.

성공적인 자연분만을 예측하는 요인에 관한 연구에서 산모의 나이 및 태아의 체중 등 신체 적인 요인이 성공적인 자연분만을 예측하는 지표가 될 수 있다는 연구는 이미 여러 차례 발 
표되었으나, ${ }^{8}$ 산모의 분만 의지 및 우울 또는 불안 정도가 자연 분만 성공률에 영향을 미치는지에 관한 연구는 거의 없다. 한 연 구에 의하면 분만 전 강력하게 자연분만을 원하는 산모가 제왕 절개로 분만한 경우 또는 제왕절개술로 분만한 산모가 자연 분 만한 산모에 비하여 산후우울증이 현저하게 증가되는 것을 확 인할 수 있었다. ${ }^{9}$

데이터가 제한적이기는 하지만 위의 결과로 미루어 볼 때 성 공적인 자연분만을 위해서는 산모의 심리 상태 및 자연분만에 대한 의지가 중요할 것으로 생각되며 따라서 본 연구에서는 산 전 우울 정도가 분만 방법에 미치는 영향 및 분만 방법이 산후 산모의 우울 정도에 미치는 영향을 알아보고자 하였다.

\section{대상 및 방법}

\section{1. 대상}

2018년 10월부터 2019년 9월까지 차의과학대학교 분당차병 원에 내원한 산모 중 본 연구에 동의한 산모 35 명을 대상으로 하 였다. 분만 방법에 영향을 미칠 수 있는 제왕절개 기왕력, 자궁 근종절제술 기왕력을 가지고 있는 산모 및 쌍태아 임신 산모, 전 치 태반, 태아 위치 이상, 거대아 등은 대상에서 제외하였다. 본 연구는 차의과학대학교 분당차병원의 윤리위원회의 승인을 받 은 후 진행되었다(IRB 2018-07-011).

\section{2. 자료 수집 방법}

연구 대상자의 기본적인 특성(나이, 직업, 교육 정도, 수입, 키, 몸무게, 산과력 등) 및 현재의 임신 주수를 수집하였고 한국어 판 에딘버러 우울 척도(Korean-Edinburgh Perinatal/Postnatal Depression Scale, K-EPDS)를 이용하여 총 10 개의 항목에 대 한 설문을 진행하였다. 각 대상군에서 재태 연령 34-36주 및 분 만 한 달 후에 시행하여 총 2 번의 설문을 진행하였다.

\section{3. 정의}

$\mathrm{EPDS}$ 기준의 경우(30점 만점), 9-10점 이상부터는 정신건강 의학 진찰을 요구하며 다수의 논문에서 12-13점 이상일 경우 우울증 확률이 높다고 보고하고 있다. 따라서 산전 또는 산후우 울증의 기준은 K-EPDS 9점으로 정의하였다. ${ }^{10,11}$

\section{4. 통계분석}

대상군의 기본적인 특성 및 EPDS는 Mann-Whitney test, 제왕절개군과 자연분만군에서의 우울증 비율의 비교는 chisquare test를 이용하였고 분만 전후 $\mathrm{K}-\mathrm{EPDS}$ 의 변화와 분만
방법의 연관성을 살펴보기 위해서는 paired test를 사용하였고, 통계프로그램은 SPSS ver. 12. (SPSS Inc., Chicago, IL, USA) 를 사용하였다.

\section{결과}

\section{1. 분만 방법에 따른 두 군 간의 특성의 비교}

총 35 명 중 제왕절개군 20 명과 자연분만군 15 명의 나이 (33.5 \pm 4.0 vs. $33.8 \pm 3.1, P=0.860$ ), 체질량지수(23.8 \pm 5.6 vs. $22.5 \pm 4.5, P=0.470)$ 및 혈압 등 기본적인 특성은 통계학적으 로 차이가 없었다. 두 군에서의 산과력 또한 통계학적으로 차이 가 없었다. 또한 제왕절개군과 자연분만군에서의 대졸 이상의 비율 $80.0 \%$ vs. $86.7 \%, P=0.600$, 월 수입 600 만 원 이상의 비 율( $25.0 \%$ vs. $46.7 \%, P=0.180)$ 도 통계학적으로 차이가 없었다 (Table 1).

\section{2. 분만 방법에 따른 분만전후 우울척도}

분만 직전 $\mathrm{K}-\mathrm{EPDS}$ 는 제왕절개군에서 7.2 점, 자연분만군에 서 5.8점으로 제왕절개로 분만한 군에서 약 2점 정도 높았으 나 통계학적으로 유의하지는 않았다 $(P=0.390)$. 분만 후 1 달 이 내에 시행한 $\mathrm{K}-\mathrm{EPDS}$ 는 제왕절개군에서 9.2점, 자연분만군에 서 7.6점으로 제왕절개로 분만한 그룹에서 약 2점 높았다 $(P=$ 0.010) (Table 1).

분만 전후 $\mathrm{K}-\mathrm{EPDS}$ 의 차이를 분석한 결과에서 제왕절개군 에서 $\mathrm{K}-\mathrm{EPDS}$ 는 2.0 점 상승하였고 자연분만군에서는 1.8 점 상 승하였으나 두 군에서의 통계학적인 차이는 없었다 $(P=0.877)$. 또한 분만 방법에 따른 분만 전후의 K-EPDS 9점 이상의 비 율을 비교한 결과 제왕절개군에서 분만 직전 측정한 $\mathrm{K}-\mathrm{EPDS}$ 상 9점 이상의 비율은 $35 \%$ (7/20), 자연분만군에서 분만 직전 K-EPDS 9점 이상의 비율은 33.3\% (5/15)였다. 분만 직후 시 행한 $\mathrm{K}-\mathrm{EPDS}$ 검사상 9 점 이상의 비율은 제왕절개군에서 $45 \%$ (9/20), 자연분만군에서 $33.3 \%$ (5/15)로 제왕절개군에서 높았 으나 통계학적으로 의미는 없었다 $(P=0.486)$ (Table 1, Fig 1B). 분만 전후 $\mathrm{K}-\mathrm{EPDS}$ 의 변화를 비교하였을 때, 제왕절개군과 자 연분만군 모두에서 분만 전에 비하여 분만 직후 $\mathrm{K}-\mathrm{EPDS}$ 의 상 승을 관찰할 수 있었고 이것은 통계학적으로도 의미 있는 변화 였다 $(P=0.039)$ (Fig 1A).

\section{3. 우울 척도에 따른 분만 방법의 비교}

분만 직전 $\mathrm{K}-\mathrm{EPDS}$ 9점 미만은 총 23명, $\mathrm{K}-\mathrm{EPDS}$ 9점 이상은 12 명이었다. K-EPDS 9점 미만인 군에서 제왕절개의 비율은 
$56.5 \%$ (13/23), 자연분만의 비율은 43.5\% (10/23)로 통계학적 유의성은 없었다 $(P=0.918)$. 분만 직전 $\mathrm{K}-\mathrm{EPDS}$ 9점 이상은 총 12 명이었으며 제왕절개의 비율은 $58.3 \%$ (7/12), 자연분만 비율 은 $41.7 \%$ (5/12)로 통계학적인 유의성은 없었다 $(P=0.919)$. 또 한 분만 직전 $\mathrm{K}-\mathrm{EPDS}$ 9점 미만(56.5\%)과 이상(58.3\%)군에서 의 제왕절개 비율은 통계학적인 차이가 없었다 $(P>0.500)$. 다만
분만 직후 K-EPDS 9점을 기준으로 분만 방법의 비율을 비교하 였을 때, $\mathrm{K}-\mathrm{EPDS}$ 9점 이상 그룹은 총 14 명으로, 제왕절개의 비 율은 $64.3 \%$ (9/14), 자연분만의 비율은 $35.7 \%$ (5/14)로 통계학 적으로 유의하게 제왕절개 비율이 높음을 알 수 있었다(64.3\% vs. $35.7 \%, P=0.010$ ) (Table 2).
A

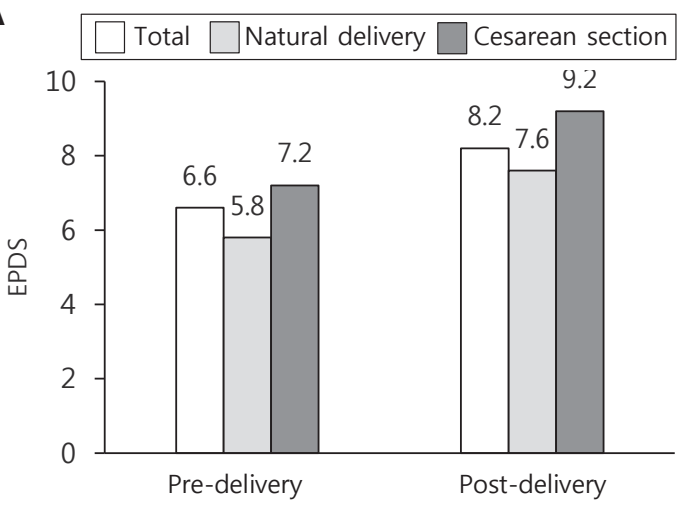

B

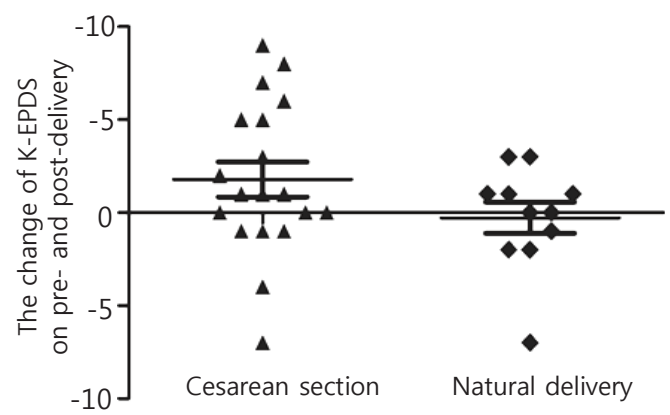

Fig. 1. The change of Korean-Edinburgh Perinatal/Postnatal Depression Scale (K-EPDS) on pre- and post-delivery. (A) The change of K-EPDS on pre- and post-delivery. (B) The difference of K-EPDS on pre- and post-delivery.

Table 1. Characteristics and K-EPDS of Study Population

\begin{tabular}{|c|c|c|c|}
\hline Characteristic & Cesarean section $(n=20)$ & Natural delivery $(n=15)$ & $P$-value ${ }^{*}$ \\
\hline Years & $33.5 \pm 4.0$ & $33.8 \pm 3.1$ & 0.86 \\
\hline $\mathrm{BMI}\left(\mathrm{kg} / \mathrm{m}^{2}\right)$ & $23.8 \pm 5.6$ & $22.5 \pm 4.5$ & 0.47 \\
\hline Degree of education (\%) & 80 & 86.7 & 0.60 \\
\hline Monthly income (six million won /month) & 25 & 46.7 & 0.18 \\
\hline \multicolumn{4}{|l|}{ Blood pressure (mmHg) } \\
\hline Systolic & $118 \pm 12$ & $113 \pm 18$ & 0.39 \\
\hline Diastolic & $73 \pm 9$ & $74 \pm 14$ & 0.76 \\
\hline \multicolumn{4}{|l|}{ Obstetric history } \\
\hline Gravidity & $2.3 \pm 1.4$ & $2.3 \pm 1.8$ & 1.0 \\
\hline Parity & $0.5 \pm 0.7$ & $0.4 \pm 0.6$ & 0.53 \\
\hline Living baby & $0.5 \pm 0.7$ & $0.4 \pm 0.6$ & 0.68 \\
\hline Artificial abortion & $0.1 \pm 0.3$ & $0.3 \pm 0.6$ & 0.44 \\
\hline Spontaneous abortion & $0.6 \pm 1.2$ & $0.6 \pm 0.9$ & 0.86 \\
\hline \multicolumn{4}{|l|}{ K-EPDS } \\
\hline Pre-delivery (gestational age 34-36 weeks) & $7.2 \pm 5.0$ & $5.8 \pm 4.7$ & 0.39 \\
\hline Post-delivery (within one month after delivery) & $9.2 \pm 4.9$ & $7.6 \pm 5.4$ & 0.01 \\
\hline The change of K-EPDS on pre- and post-delivery & $2.0 \pm 4.1$ & $1.8 \pm 5.0$ & 0.877 \\
\hline Pre-delivery (the ratio of >K-EPDS 9 score) & $7(35)$ & $5(33.3)$ & 0.918 \\
\hline Post-delivery (the ratio of >K-EPDS 9 score) & $9(45.0)$ & $5(33.3)$ & 0.486 \\
\hline
\end{tabular}

Values are presented as mean \pm standard deviation or number (\%).

Abbrevaitions: BMI, body mass index; K-EPDS, Korean-Edinburgh Perinatal/Postnatal Depression Scale.

*Mann-Whitney test, paired test. 
Table 2. Delivery mode according to K-EPDS

\begin{tabular}{lccc}
\hline & Cesarean section $(\mathrm{n}=20)$ & Natural delivery $(\mathrm{n}=15)$ & $P_{\text {-value }}$ \\
\hline Pre-delivery K-EPDS $<9(\mathrm{n}=23)$ & $13(56.5)$ & $10(43.5)$ & 0.918 \\
Pre-delivery K-EPDS $\geq 9(\mathrm{n}=12)$ & $7(58.3)$ & $5(41.7)$ & 0.919 \\
Post-delivery K-EPDS $<9(\mathrm{n}=21)$ & $11(52.4)$ & $10(47.6)$ & 0.486 \\
Post-delivery K-EPDS $\geq 9(\mathrm{n}=14)$ & $9(64.3)$ & $5(35.7)$ & 0.010 \\
\hline
\end{tabular}

Values are presented as number (\%).

Abbrevaitions: K-EPDS, Korean-Edinburgh Perinatal/Postnatal Depression Scale.

${ }^{*}$ Chi-square test.

\section{고찰}

우울과 불안은 임신 중 산모가 겪는 흔한 증상 중 하나이다. 하지만 실제 진료 현장에서는 태아의 안녕과 산모의 신체적인 변화에 초점이 맞추어 진료가 이루어지고 있으며, 산모의 우울 과 불안이 산과적 합병증과 관련이 있다는 것이 알려져 있지만 여러 가지 현실적인 문제로 인하여 산모의 불안과 우울 정도에 대한 평가는 이루어지지 않고 있고 그 중요성이 간과되고 있는 상태이다. ${ }^{1,3}$ 특히 분만 방법이 산후우울증에 미치는 영향에 대 해서는 오랜 기간에 걸친 연구 및 메타분석에 의하여, 제왕절개 로 분만한 산모는 자연분만 산모에 비하여 산후우울증의 빈도 가 높고 이에 따라서 제왕절개를 통한 분만이 산후우울증의 위 험 요소가 될 가능성이 있는 것으로 밝혀졌다. ${ }^{7}$

본 연구 결과에서도 제왕절개로 분만한 산모에서 분만 후 1 달 이내에 시행한 K-EPDS는 자연분만군에서보다 높았고, 통 계학적으로 유의한 차이를 보였다. 이러한 결과는 이미 여러 연 구를 통하여 밝혀졌지만 국내 산모를 대상으로 한 연구 결과는 현재까지 없었다. 또한 제왕절개군과 자연분만군에서 각각 분 만 전후의 $\mathrm{K}-\mathrm{EPDS}$ 의 변화를 비교하였을 때, 두 군 모두에서 $\mathrm{K}-\mathrm{EPDS}$ 가 상승하였으나 분만 방법에 따른 통계학적인 의미는 없었다. 하지만 분만 전후의 $\mathrm{K}-\mathrm{EPDS}$ 의 상승은 제왕절개 및 자 연분만군 모두에서 통계학적으로 유의미한 증가임을 알 수 있었 다. 이는 분만 방법과 상관없이 분만 자체가 산모의 우울감을 증 가시킬 수 있으며 이러한 연구 결과를 토대로 분만 후 내원한 산 모에서 산후우울에 대한 평가가 필요하다는 이론적 근거가 될 수 있을 것으로 생각한다.

$\mathrm{K}$-EPDS 9점을 기준으로 분만 방법에 따른 특성을 비교하였 을 때 자연분만군에서 분만 전후 K-EPDS 9점 이상의 비율은 변 화가 없는 반면 $\mathrm{K}-\mathrm{EPDS}$ 9점 이상이 2명 증가한 것을 관찰할 수 있었다(분만 전 vs. 분만 후: $35 \%$ [7/20] vs. $45.0 \%$ [9/20]). 비록 연구 규모가 작아서 모든 결과에서 통계학적으로 유의한 결과를 얻을 수는 없었으나 제왕절개가 분만 후 우울의 척도를 증가시킬 수 있는 요소라는 것은 본 연구에서도 확인할 수 있었다. 또한 분
만 후 K-EPDS 9점을 기준으로 제왕절개와 자연분만 비율을 비 교하였을 때 K-EPDS 9점 이상 군(14명)에서 제왕절개의 비율 은 64.3\% (9/14), 자연분만의 비율은 $35.7 \%$ (5/14)로 통계학적 으로 유의하게 제왕절개 비율이 높음을 알 수 있었다. 이는 제왕 절개의 결과일수도 있겠으나 본 연구 결과 및 이전에 발표된 많 은 논문을 토대로 제왕절개 자체가 산후우울증의 척도를 상승시 킬 수 있다는 것을 다시 한번 확인할 수 있었다. 본 연구의 목적은 산전 우울 정도가 분만 방법에 미치는 영향 및 분만 방법이 산후 산모의 우울 정도에 미치는 영향을 알아보고자 하는 것이었다.

분만 전 산모의 우울 정도가 분만 방법에 영향을 알아보기 위하 여 본 연구에서는 임신 34-36주에 산모의 우울 정도를 K-EPDS 를 이용하여 설문으로 조사하였다. 그 결과 분만 직전 $\mathrm{K}-\mathrm{EPDS}$ 는 제왕절개군에서 자연분만군보다 약 2점 정도 높았으나 적은 연 구 규모로 인하여 통계학적으로 유의한 결과를 도출하지는 못 하였다. 하지만 분만 이후의 산모의 우울 정도는 정신과적 상담 을 요구하는 K-EPDS 9점 이상에서 제왕절개로 분만한 비율이 자연분만 비율보다 높았으며, 분만 후 시행한 $\mathrm{K}$-EPDS의 평균 도 제왕절개군에서 유의하게 높은 것으로 볼 때 제왕절개가 산 후우울증에 미치는 영향은 큰 것을 확인할 수 있었다.

분만 방법은 산모 및 태아의 객관적인 신체 상태뿐 아니라 여 러 가지 복합적인 요인에 영향을 받는 것으로 알려져 있다. ${ }^{1}$ 하 지만 지금까지의 연구는 모두 분만 이후 산모의 우울증에 초점 을 맞추었고, 분만 직전인 임신3분기에 산모의 우울 정도가 분 만 방법에 영향을 미치는지에 대한 연구는 거의 시행되고 있지 않다. 본 연구는 분만 후뿐만 아니라, 분만 전 산모의 우울 정도 에 대한 의료진의 관심의 중요성을 강조하고자 진행된 예비 연 구 결과이다. 물론 분만 방법은 제왕절개의 적응증 및 분만 경험 의 유무에 크게 영향을 미친다. 하지만 본 연구는 적은 연구 대상 의 수로 인해 여러 가지 조건을 완벽하게 배제하지 못한 한계가 있다. 향후 연구를 통하여 조금 더 큰 규모의 연구 및 분만 방법 에 영향을 미치는 여러 요인을 조사하고 대상군을 잘 선별한다 면 분만 전 산모의 우울 정도가 분만 방법에 미치는 영향에 대한 좋은 결과를 도출할 수 있을 것으로 기대한다. 


\section{Conflict of interest}

No potential conflict of interest relevant to this article was reported.

\section{References}

1) Staneva A, Bogossian F, Pritchard M, Wittkowski A. The effects of maternal depression, anxiety, and perceived stress during pregnancy on preterm birth: a systematic review. Women Birth 2015;28:179-93.

2) Nasreen HE, Pasi HB, Rifin SM, Aris MAM, Rahman JA, Rus RM, et al. Impact of maternal antepartum depressive and anxiety symptoms on birth outcomes and mode of delivery: a prospective cohort study in east and west coasts of Malaysia. BMC Pregnancy Childbirth 2019;19:201.

3) Grote NK, Bridge JA, Gavin AR, Melville JL, lyengar S, Katon WJ. A metaanalysis of depression during pregnancy and the risk of preterm birth, low birth weight, and intrauterine growth restriction. Arch Gen Psychiatry 2010;67:1012-24.

4) Grigoriadis S, Graves L, Peer M, Mamisashvili L, Tomlinson G, Vigod SN, et al. Maternal anxiety during pregnancy and the association with adverse perinatal outcomes: systematic review and meta-analysis. Clin Psychiatry 2018;79:17-12011.

5) Kuo SY, Chen SR, Tzeng YL. Depression and anxiety trajectories among women who undergo an elective cesarean section. PLoS One 2014;9: e86653.

6) Wu J, Viguera A, Riley L, Cohen L, Ecker J. Mood disturbance in pregnancy and the mode of delivery. Am J Obstet Gynecol 2002;187:864-7.

7) Xu H, Ding Y, Ma Y, Xin X, Zhang D. Cesarean section and risk of postpartum depression: a meta-analysis. J Psychosom Res 2017;97:118-26.

8) Alavifard S, Meier K, Shulman Y, Tomlinson G, D'Souza R. Derivation and validation of a model predicting the likelihood of vaginal birth following labour induction. BMC Pregnancy Childbirth 2019;19:130.

9) Houston KA, Kaimal AJ, Nakagawa S, Gregorich SE, Yee LM, Kuppermann M. Mode of delivery and postpartum depression: the role of patient preferences. Am J Obstet Gynecol 2015;212:229.e1-7.

10) Han K, Kim MJ, Park J. The Edinburgh Postnatal depression Scale, Korean Version: reliability and validity. J Korean Soc Biol Ther Psychiatry 2004;10: 201-7.

11) Ahn CS, Kang MS, Park SY, Choi YR. Usefulness of Edinburgh Postnatal Depression Scale for Postpartum Depression. Korean J Perinatol 2015; 26:21-7. 